\title{
Matching Neural and Muscle Oscillators: Control by FMRFamide-like Peptides
}

\author{
Pierre Meyrand a and Eve Marder \\ Biology Department, Brandeis University, Waltham, Massachusetts 02254
}

\begin{abstract}
Stomatogastric nervous systems of the shrimp, Palaemon serratus, were stained with antisera raised against the peptide FMRFamide. FMRFamide-like immunoreactivity was found in fibers in the input nerve to the stomatogastric ganglion (STG), in several STG somata, in dense neuropil in the STG, in the motor nerves that innervate the dilator muscles of the pyloric region, but not in the pyloric dilator (PD) motor neurons. FMRFamide and several FMRFamide-like peptides elicited sequences of rhythmic depolarizations and contractions of the pyloric dilator muscle. As peptide concentrations were increased, a discrete threshold for contraction was found, above which contractions were initiated with a decreasing latency in an all-or-none fashion. Muscles stopped rhythmically contracting after many seconds to several minutes of activity; the duration of spontaneous oscillatory activity in peptide was proportional to the concentration of applied peptide. In the absence of peptide, each motor neuron discharge evoked small graded muscle contractions. During peptide-induced oscillations, motor neuron activity did not always entrain muscle oscillations. After spontaneous oscillations had stopped, when the motor neurons were stimulated in the presence of the peptide, each motor neuron burst evoked large amplitude contractions as a result of the peptide-induced regenerative properties of the muscle membrane.
\end{abstract}

Rhythmic movements often result from rhythmic activity in central neural networks. In many cases, though the neural output may be oscillatory, the muscles activated by these rhythmic motor systems contract only when driven. Because most vertebrate skeletal muscle fibers generate action potentials, muscle contraction is not critically sensitive to the amplitude of the postsynaptic response as long as it is sufficient to depolarize the muscle to threshold. In contrast, many invertebrate muscle fibers do not routinely display regenerative membrane properties, but the amplitude of muscle contraction is a function of the size of the postjunctional response (Atwood, 1976). Under these conditions movement amplitude can be extremely sensitive to

\footnotetext{
Received Aug. 14, 1990; revised Nov. 16, 1990; accepted Nov, 20, 1990.

We thank Dr. William Chapple for the design of the force-displacement transducer and Mr. Michael O'Neil for its construction. We thank Dr. Win Watson III for supplying FMRFamide antibody 231, and the Moulins lab, Arcachon, for providing shrimp. Drs. Nancy Kopell and Irving Epstein gave us invaluable advice about oscillators. Supported by URI Contract F49620-86-C-0131 to N. Kopell, NS-17813 (E.M.) and NATO Travel Grant 0540/86.

Correspondence should be addressed to Dr. Eve Marder, Department of Biology, Brandeis University, Waltham, MA 02254.

Present address: Laboratoire de Neurobiologie, et Physiologie Comparées, CNRS et Université de Bordeaux I, Arcachon, France 33120.

Copyright (C) 1991 Society for Neuroscience $0270-6474 / 91 / 111150-12 \$ 03.00 / 0$
}

the pattern of activity in the motor neurons, as activity-dependent processes such as facilitation (Dixon and Atwood, 1989) play an important role in controlling contraction amplitude. In recent years it has become clear that some muscles display conditional regencrative propertics (Calabresc, 1989), bccausc modulatory substances such as amines and peptides (Lingle, 1981; Glusman and Kravitz, 1982; Meyrand and Moulins, 1986) can elicit myogenic activity.

Rhythmic movements that depend on myogenic properties, such as those of the vertebrate heart and gut, can continue without precise timing information from the CNS. Many oscillators can only be entrained at a frequency close to their natural one. Therefore, if a rhythmic motor discharge varies over a large frequency range, the presence of strong intrinsic oscillatory activity in a muscle could, in principle, lead to an inability of the muscle to be entrained over the full frequency range of rhythmic neural inputs. Thus, understanding how rhythmic neural inputs interact with a rhythmically active muscle requires understanding how these oscillators interact.

In the heartbeat system of the leech the peptide FMRFamide enhances the amplitude and frequency of small myogenic oscillations in the muscles of the heart tube (Kuhlman et al., 1985; $\mathrm{Li}$ and Calabrese, 1987), and the excitatory motor neurons to these muscles can entrain this myogenic rhythm (Maranto and Calabrese, 1984; Calabrese, 1989). In a previous study on the dilator muscle of the shrimp stomatogastric system, Meyrand and Moulins (1986) showed that dopamine induces myogenic contractions of the dilator muscle that can also be entrained by rhythmic neural activity.

The stomatogastric nervous systems of the large decapod crustaceans such as lobsters and crabs contain several neuropeptides thought to have neuromodulatory functions (Hooper and Marder, 1984; Marder, 1987; Marder et al., 1987; Marder and Nusbaum, 1989). Among these are one or more FMFRamide-like peptides (Hooper and Marder, 1984; Callaway et al., 1987; Marder et al., 1987). Immunocytochemical studies of the shrimp stomatogastric nervous system show FMRFamide-like peptides are present in the motor nerves of the pyloric chamber, suggesting a neuromuscular target for one or more FMRFamidelike peptides in shrimp.

In control saline the dilator muscle of the pyloric chamber of the stomach is inactive, and responds to nerve stimulation with a small, graded contraction (Meyrand and Moulins, 1986). In this paper we show that FMRFamide-like peptides evoke sequences of rhythmic depolarizations and contractions, followed by a state in which the muscle does not spontaneously contract but is close to threshold for the generation of rhythmic activity. Under these conditions intrinsic regenerative properties of the muscle itself are easily triggered by neural inputs. Some of these data have been presented in abstract form (Meyrand et al., 1987). 


\section{Materials and Methods}

Animals. Pink shrimp, Palaemon serratus, were obtained from fishermen in Royan, France, and maintained in circulating aerated sea water until used. Seventy-six animals $7-10 \mathrm{~cm}$ in length were used.

Movement recordings. Single bundles of the shrimp dilator muscle were used. Single bundles are too small for commercially available forcemovement transducers, so movements were recorded using a transducer made by M. O'Neil with a modified design from W. Chapple. Briefly, this transducer was constructed using 4 Kulite Semiconductor Products semi-conductor strain gages model AGP-1000-300 in a bridge configuration and an Analog Devices High Performance Economy Strain Gage/ RTD Conditioner model $2 \mathrm{~B} 31$.

Cardiopyloric valve (cpvl) muscle. Cpvl muscles with attached nerve were dissected as described in Meyrand and Moulins (1986). The cpvl muscle has 3 bundles of 10-12 electrically coupled muscle fibers. Fibers within a bundle contract synchronously, but the 3 bundles are not coupled and therefore contract asynchronously unless they receive synchronous neural inputs. Control experiments involving simultaneous intracellular recordings from 2 or more muscle fibers within a bundle showed that the entire muscle bundle is virtually isopotential.

Intracellular recordings. Conventional electrophysiological methods were used. Microelectrodes were filled with $2.5 \mathrm{M} \mathrm{KCl}$, and had resistances of 15-25 M . All experiments requiring current injection were done with 2 independent microelectrodes.

Immunocytochemistry. Whole-mount immunocytochemistry was done as previously described for FMRFamide-like peptides (Marder et al., 1987). Antiserum 231 (O'Donohue et al., 1984; Watson et al., 1984) was a gift of T. O'Donohue and W. Watson III and was used at 1:300. Antiserum 671 was described in Marder et al. (1987) and was used at 1:600. Secondary antibodies were 1:25 goat anti-rabbit IgG labelled with fluorescein or rhodamine obtained from either Boehringer-Mannheim or Cappel. Preparations were viewed and photographed on a Zeiss IM-35 epifluorescence microscope.

Control experiments in which the antisera were preincubated with known peptides were performed to test the specificity of the antisera for FMRFamide-like peptides in the shrimp tissue. Preincubation with the peptide, proctolin $\left(10^{-5} \mathrm{M}\right)$ produced no block of the staining. In contrast, preincubation of the antiserum with $\left(10^{-6}-10^{-4}\right) \mathrm{M}$ FMRFamide and related peptides such as YGGFMRFamide abolished staining.

Double labels. Pyloric dilator (PD) motor neurons were identified electrophysiologically on the basis of their ability to evoke excitatory junctional potentials in the cpvl muscle. Neurons were filled by intracellular injection of Lucifer yellow $\mathrm{CH}$, fixed in paraformaldehyde, and then treated for immunocytochemistry (antibody 231), as previously described (Marder et al., 1987), using rhodamine-labeled secondary antibodies. Double labels were viewed and photographed by switching between fluorescein (Lucifer yellow) and rhodamine filter sets.

Peptides. TNRNFLRFamide was synthesized and purified by James Wiemann at Brandeis University. All other peptides were purchased from commercial sources (Peninsula Labs, Bachem, or Sigma).

\section{Results}

\section{Localization of FMRFamide-like immunoreactivity}

The stomatogastric nervous system of crustaceans, including the shrimp, consists of 4 ganglia, the paired commissural ganglia (CoGs), the esophageal ganglion (OG), and the stomatogastric ganglion (STG; Fig. 1). The STG is connected to the OG and the $\mathrm{CoGs}$ via a single input nerve, the stomatogastric nerve (stn; Fig. 1). The shrimp STG contains about 25 neurons, some of which are motor neurons that innervate muscles of the pyloric region (Meyrand and Moulins, 1988a,b).

Previous work in lobsters and crabs (Marder et al., 1987) showed FMRFamide-like immunoreactive neurons in the CoGs and OG. In these species, staining was seen in the stn and in neuropilar projections in the STGs. When we stained wholemount preparations of the stomatogastric nervous systems of the shrimp with 2 different FMRFamide antisera we found patterns of staining similar, but not identical, to those seen in larger decapods.

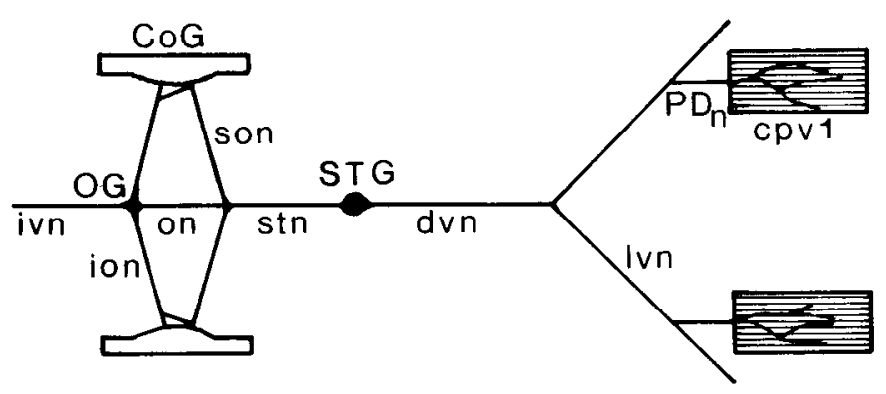

Figure 1. Stomatogastric nervous system of the shrimp, Palaemon serratus. This schematic drawing shows the positions of the 4 ganglia of the stomatogastric nervous system. The stomatogastric ganglion (STG) is connected to the paired commissural ganglia $(C O G)$ and an unpaired esophageal ganglion $(O G)$ by the stomatogastric nerve $(s t n)$. The somata of the pyloric dilator $(P D)$ motor neurons are in the STG. The PD neurons innervate the $c p v 1$ (cardio pyloric valve 1) muscle via the dorsal ventricular nerve $(d v n)$ and the lateral ventricular nerve $(l v n)$. Other abbreviations: ion, inferior esophageal nerve; ivn, inferior ventricular nerve; on, esophageal nerve; $P D n$, pyloric dilator nerve; son, superior esophageal nerve.

Figurc $2 A$ shows a wholc-mount STG preparation stained with antiserum 231. Note the dense staining throughout the neuropil, as seen in the other crustaceans studied (Hooper and Marder, 1984; Callaway et al., 1987; Marder et al., 1987), and the stained fibers (3-5) in the stn. However, in contrast to the large crustaceans, the shrimp STG showed 2 or 3 stained somata in whole-mount preparations (Fig. $2 A$ ). One of the stained somata is large and was seen in all the preparations. One or 2 smaller somata were also seen in 20 preparations using antiserum 231 and in 7 preparations using antiserum 671.

Stained fibers were also seen in some of the motor nerves of the stomatogastric nervous system. The unpaired dorsal ventricular nerve (dvn) showed at least 2 well stained fibers (Fig. $2 B$ ), one of which can be traced to each lateral ventricular nerve (lvn; Fig. 2C). These fibers were visible the length of the lvn, and were also seen in the nerves innervating the cpvl dilator muscles of the pyloric chamber (Fig. 2D).

To determine whether the PD motor neurons themselves contained FMRFamide-like immunoreactivity, PD somata were filled with Lucifer yellow, the dye was allowed to diffuse, and the preparations were subsequently processed to visualize FMRFamide-like immunoreactivity (Fig. 3). In the preparation shown in Figure 3, the 2 PD somata were injected with Lucifer yellow. The 2 somata were partially overlapping and in this plane of focus they appear as 1 large, irregular shape (Fig. $3 A$ ). Figure $3 A$ shows the filled cells and 2 large processes extending into the dvn ( 1 from each filled neuron). Figure $3 B$ shows a higher magnification view of the dvn as it extends towards the periphery. The 2 large motor axons each branch to send an axon into each lvn and a total of 4 large Lucifer yellow stained axons are seen just anteriorly to the point at which the dvn splits to form the lvn. Figures 3, $C$ and $D$ are the same positions and magnifications as Figures $3, A$ and $B$, now viewed with the rhodamine filter set to visualize the location of the FMRFamidelike immunoreactivity. Figures $3, C$ and $D$, illustrate that the FMRFamide-like immunoreactivity is not present in the PD somata or their axons. The open downward arrow in Figure $3 C$ shows the position of the unstained PD somata. A comparison of the pattern in Figure 3, $B$ and $D$, shows that the FMRFamide- 

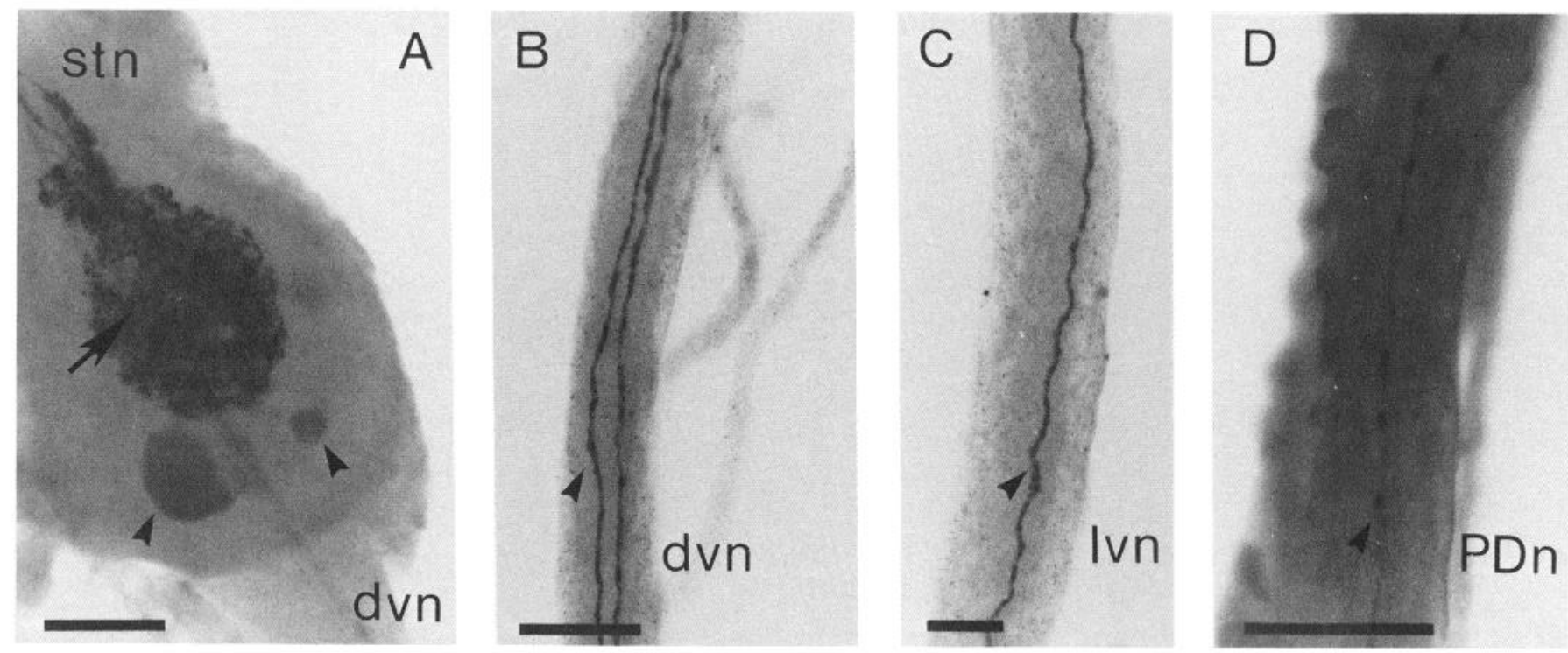

Figure 2. Distribution of FMRFamide-like immunoreactivity in the STG and motor nerves. Preparations were reacted as whole-mounts as in Marder et al. (1987). A, Whole-mount of an STG of Palaemon serratus stained with 1:300 dilution of antiserum 231. Note the dense neuropilar staining (black arrow). Two stained somata (one large and one small; arrow heads) are visible. Stained fibers in the dvn are out of focus. B, Two stained fibers (arrowhead) in the dvn. C, Stained fiber (arrowhead) in the lvn. D, PDn shows stained fiber (arrowhead). Calibration bars are 100 $\mu \mathrm{m}$ in all panels.

like fibers are smaller in diameter than the PD axons, and that they run in a different portion of the nerve. Indeed, their position is indicated by the small upward arrow in Figure $3 B$, which shows a faint signal from the rhodamine stain "breaking through" into the fluorescein filter. A small amount of "break through" is also seen in Figure $3 A$ where faint fibers in the stn (left of ganglion) are seen. These data demonstrate that the PD axons are not the source of the FMRFamide-like immunoreactivity in the peripheral nerves of the pyloric region. We have not been able to ascertain the source of the cells that give rise to these FMRFamide-like projections.

\section{Physiological effects of FMRFamide related peptides on the PD muscles}

When isolated, the PD muscle (cpv1) is frequently quiescent and passive. However, on rare occasions spontaneous rhythmic contractions are seen subsequent to isolation. Previous work showed that dopamine applications evoke rhythmic contractions associated with repeating depolarizations of membrane potential that show all the properties of endogenous oscillations (Meyrand and Moulins, 1986). These oscillatory properties are not always expressed, but are conditional. The presence of FMRFamide-like immunoreactive fibers in the motor nerves to the pyloric region suggested that FMRFamide-like peptides might also influence the expression of the oscillatory properties of these muscles.

A large number of FMRFamide-like peptides have been isolated from a variety of species (Price and Greenberg, 1989). Because we do not know the sequence of the shrimp FMRFamide-like peptides, we were interested to determine the relative potencies of several different FMRFamide-like peptides on this preparation.

Cpvl muscles with a small piece of motor nerve were dissected from the animal, placed in a small dish, and attached to a movement transducer. Peptides were superfused over the mus- cle, and movement recorded in response to a variety of peptides at different concentrations. Figure 4 shows the response of a muscle to a just threshold concentration of $2.2 \times 10^{-7} \mathrm{M}$ YGGFMRFamide. After a delay (in this case almost $2 \mathrm{~min}$ ) the muscle began to oscillate, did so for about $1 \mathrm{~min}$, and then stopped.

Dose dependence of peptide actions. When movement is used as the indicator of the physiological action of the peptides, the dose-response relationships for these peptides are not graded but show a sharp threshold for activation. Figure 5 shows the response of an isolated muscle to increasing concentrations of FMRFamide. As the concentration was increased, the latency to the onset of contractions decreased (Figs. 5, 6) but the amplitude and the maximal frequency of the oscillations recorded during the first $30 \mathrm{sec}$ were the same at all concentrations (Fig. 7).

As peptide concentrations increased, the latency decreased exponentially, regardless of the order in which the different peptide concentrations were applied. Under our conditions we estimated the time constant of fluid exchange in the bath to be about $30 \mathrm{sec}$. Thus, the variation in latency with peptide concentration shown in Figure 6 is not merely a reflection of the time required for the bath to reach concentration, but represents a real variation in latency with peptide concentration.

When data from 16 preparations were pooled, FMRFamide concentrations less than or equal to $2 \times 10^{-7} \mathrm{M}$ elicited contractions in $0 / 16$ times, while concentrations of $2.5 \times 10^{-7} \mathrm{M}$ or higher elicited contractions in 29/30 times. YGGFMRFamide elicited contractions at concentrations of $2 \times 10^{-7} \mathrm{M}$ or less in 0/27 times but evoked contractions at higher concentrations in 39/41 applications. Helix peptide (Price et al., 1985) evoked contractions in $2 \times 10^{-7} \mathrm{M}$ in $0 / 12$ cases but elicited contractions in $21 / 22$ cases in higher concentrations.

Several other peptides were less effective. FLRFamide produced contractions in $0 / 6$ applications at $10^{-6} \mathrm{M}$ or lower but 

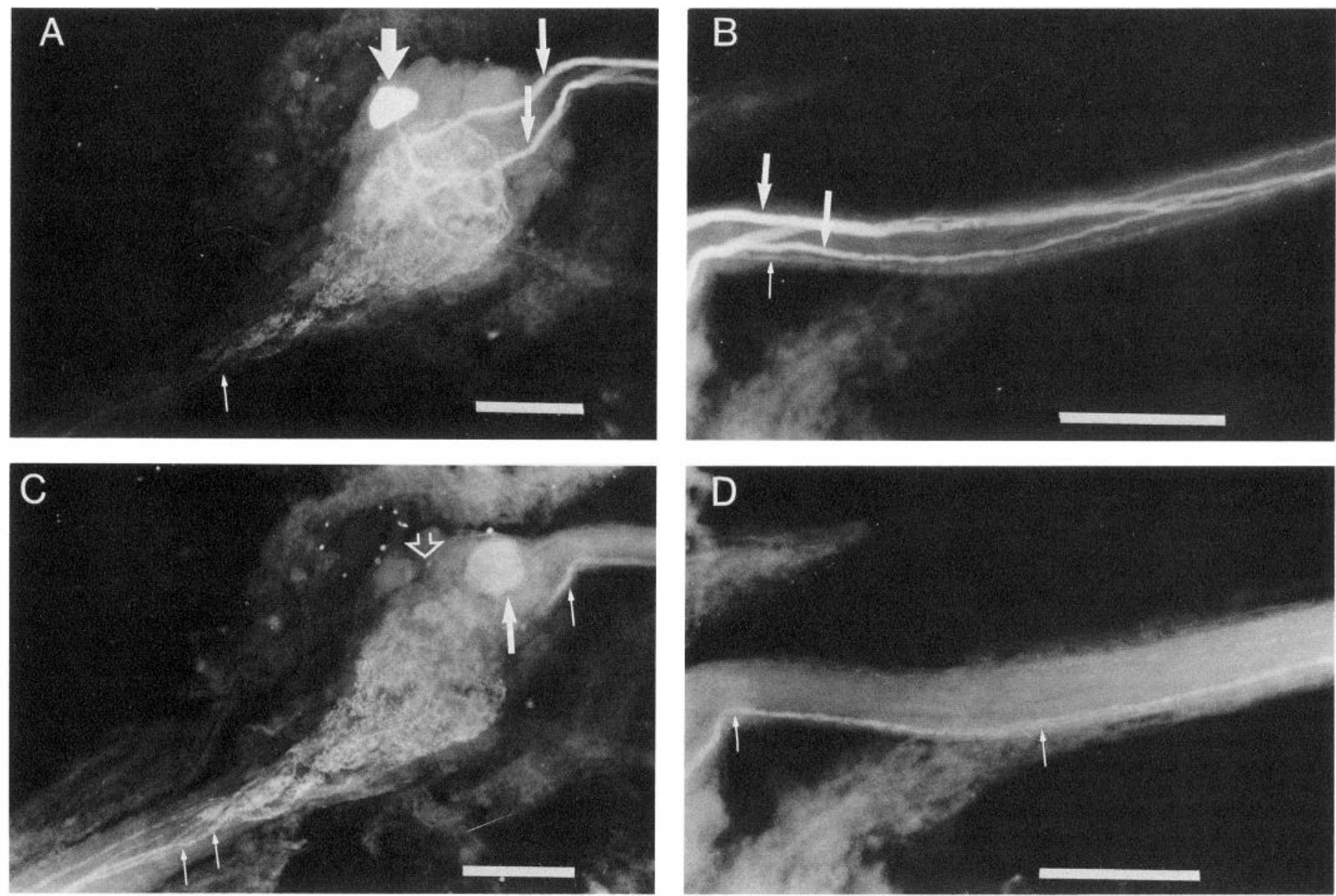

Figure 3. PD neurons are not FMRFamide-like immunoreactive. $A$, Whole-mount view of the STG. Two PD somata were injected intracellularly with Lucifer yellow. The somata were overlapping slightly, in this plane of focus they appear as a single filled shape (large downward white arrow). Exiting from the ganglion (top right) into the dvn are the filled axons of the PD neurons (smaller downward white arrows). B, Higher magnification view continuing down the dvn. The filled axons of the PD neurons (downward white arrows) are seen to branch. Faint rhodamine signal (small upward white arrow), seen "breaking through," indicates that the Lucifer-filled axons are not in the same position as the rhodamine labeled immunoreactive fibers. $C$, Same plane of focus and position as $A$, but preparation viewed with the rhodamine filter set. Note the large immunoreactive cell (upward white arrow) is not in the position of the PD neurons (shown by the downward unfilled arrow). Note the dense immunoreactivity in the neuropil and in fibers in the stn (lower left in the pictures here). $D$, Same focal plane and position as $B$, viewed with rhodamine filters. Small upward arrows show the location of the FMRFamide-like fibers in the dvn (the position of these is seen faintly in $B$, above). Calibration bars are $100 \mu \mathrm{m}$ in all panels.

was effective in $4 / 5$ trials at higher concentrations. Ineffective up to concentrations as high as $10^{-5} \mathrm{M}$ were Met-enkephalin $(0 /$ 5), LPLRFamide (0/3) and RFamide (0/4).

TNRNFLRFamide, purified and sequenced from Homarus americanus by Trimmer et al. (1987) had the lowest threshold of all peptides tested [ $57 \%$ of the muscles tested $(n=7)$ produced rhythmic contractions at $10^{-8} \mathrm{M}$ ]. However, this excitatory effect decreased at higher concentrations, until at $10^{-6} \mathrm{M}, 85.8 \%$ of the muscles failed to produce rhythmic contractions $(n=7)$.

Peptide-evoked rhythmic muscle contractions did not persist

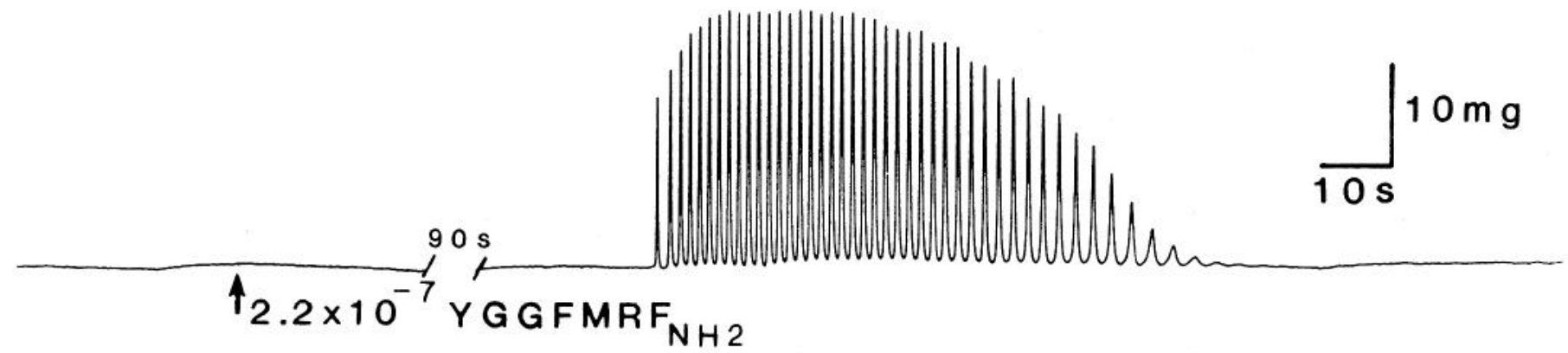

Figure 4. Rhythmic muscle contractions activated by peptide. $2.2 \times 10^{-7} \mathrm{M}$ YGGFMRFamide (upward arrow) induced bout of rhythmic contractions after a delay of about $120 \mathrm{sec}$. Contractions lasted for about $1 \mathrm{~min}$ and then stopped. 


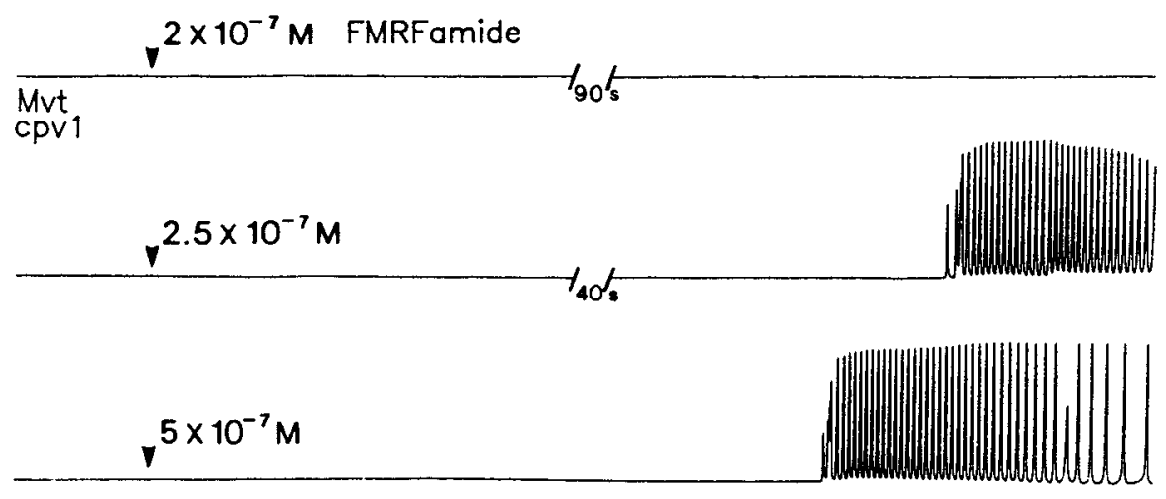

Figure 5. The latency, amplitude, and

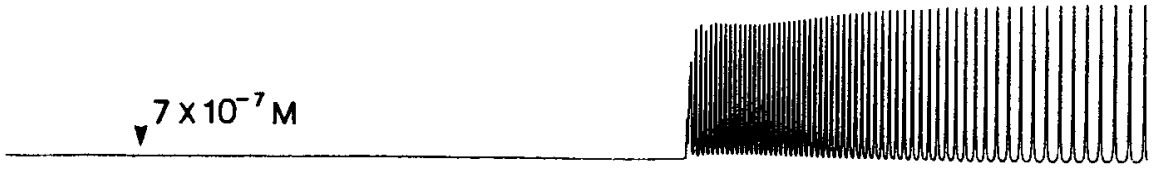
requency of FMRFamide-evoked oscillations as a function of peptide concentration. Movement recordings of single muscle bundle. At the downward arrow heads the indicated concentration of FMRFamide was applied to the bath. $2 \times 10^{-7} \mathrm{M}$ FMRFamide failed to elicil rhythmic contractions in the $280 \mathrm{sec}$ shown here, or after $15 \mathrm{~min}$ at this concentration (not shown).

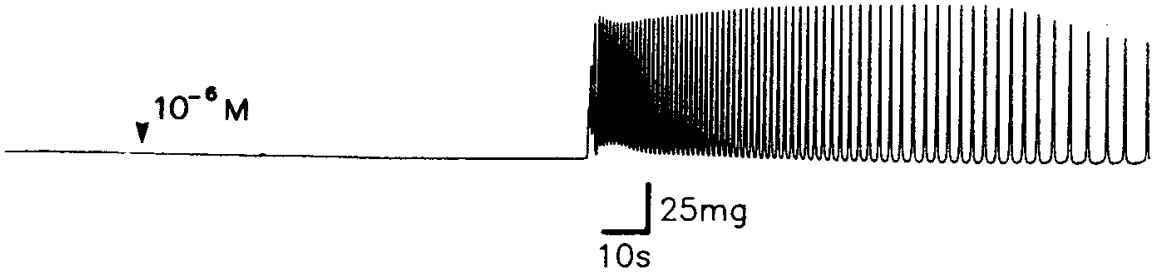

throughout long exposures of the muscle to peptide applied at either high or low concentrations. All of the FMFRamide-like peptides produced sequences of rhythmic contractions in which the duration of the sequence was proportional to the concentration of applied peptide. High peptide concentrations produced sequences of rhythmic activity as long as 300 sec.

Effects of peptides on membrane potential. The rhythmic contractions in the presence of the peptide were associated with rhythmic depolarizations (Fig. 8) that preceded and were timelocked to the contractions of the muscle. The addition of FMRFamide-like peptides to a nonactive preparation first caused a small depolarization of the muscle fiber without muscle contraction. After the fiber's membrane potential reached threshold, slow depolarizations, resembling pacemaker potentials, were followed by fast, spikelike events.

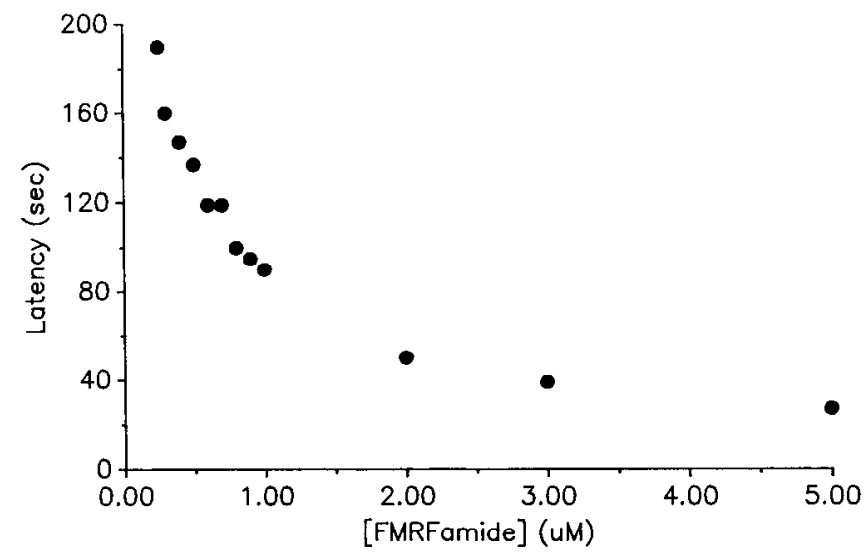

Figure 6. Plot of latency to onset of contractions as a function of peptide concentration. These data come from the same experiment as Figure 5.
The peptide-induced changes in membrane potential were unaffected by bath application of TTX (data not shown). The TTX insensitivity of the oscillations suggests that they do not depend on presynaptic action potentials and that a TTX-sensitive $\mathrm{Na}^{+}$current is not required for these oscillations. In contrast, peptide-induced membrane potential oscillations and movements were entirely suppressed by $\mathrm{Co}^{2+}$ and other $\mathrm{Ca}^{2+}$ blockers (data not shown), suggesting that an inward $\mathrm{Ca}^{2+}$ current is required for the depolarization and contraction.

To begin to characterize the mechanism by which the FMRFamide-like peptides excite the dilator muscles, we measured the effects of these peptides on the resting potential and on the apparent membrane input resistance. The resting potential depolarized by $5-10 \mathrm{mV}$ in $2.5 \times 10^{-7} \mathrm{M}$ FMRFamide, YGGFMRFamide or Helix peptide (Fig. 8). Figure $9 \mathrm{~A}$ shows a slow time base recording from a fiber in which hyperpolarizing current pulses were passed before, during, and after peptide application. Figure $9 B$ shows expanded recordings at each of these times to illustrate the change of resistance at each segment of the slow record. Figure $9 C$ shows a current-voltage curve for the fiber. These data indicate that the small depolarization of the resting membrane potential was associated with a $20 \%-30 \%$ resistance increase in the hyperpolarized region of the currentvoltage curve (Fig. 9C). During the wash the repolarization of the membrane preceded the return of the resistance to control values. In the absence of peptide, it was possible to depolarize the muscle fiber as much as $30 \mathrm{mV}$ (Fig. 9) without evoking substantial movement or eliciting action potentials. In the presence of peptide (Fig. 9), even small depolarizations were associated with large conductance increases and movements that made it impossible to depolarize the membrane past $-45 \mathrm{mV}$.

Peptide oscillations are intrinsic to muscle. A classical test for an independent oscillator is its ability to be reset by a brief stimulus during its ongoing rhythm. Figure 10 illustrates that the cpv1 muscle behaves as a true oscillator when spontaneously 


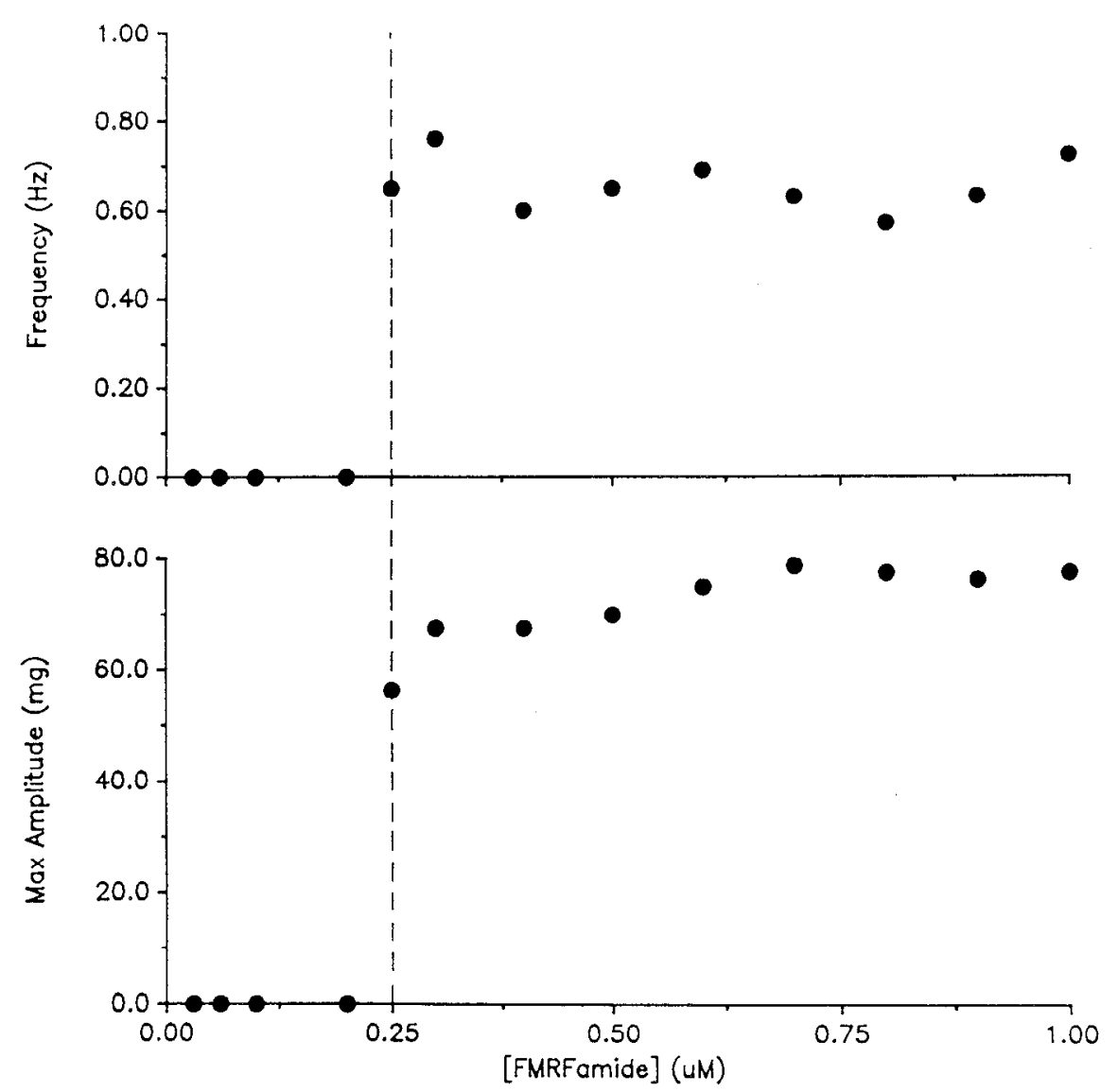

Figure 7. Plot of amplitude and frequency of oscillations in first $30 \mathrm{sec}$ as a function of peptide concentration. From the same experiment as Figure 5.

contracting in the presence of peptide. In this experiment a brief intracellular injection of depolarizing current during an oscillatory sequence of rhythmic movement produced a premature muscle contraction. After the depolarizing pulse, the muscle fiber continued to oscillate at the same frequency as previous to the pulse, but the contractions were phase advanced (the arrows in Fig. 10 indicate the times at which the rhythmic contractions would have occurred in the absence of the pulse). This confirms that the spontaneous oscillations that occur in the presence of peptide are an inherent property of the muscle.

Figure 11 shows that FMRFamide-like peptides do not merely depolarize the fibers into the range of membrane potentials at which the fibers can oscillate but also modulate the muscle fiber membrane properties. In control saline, when the fiber was depolarized by a pulse of intracellularly injected current, the membrane potential followed passively regardless of the membrane potential to which the fiber was depolarized. YGGFMRFamide was then applied to the muscle and the muscle fiber was repetitively depolarized by pulses of current of the same amplitude as that given during the control (Fig. $11 B$ ). At $t=0$ the response was comparable to the control, because the peptide solution had just entered the bath but had not reached final concentration.

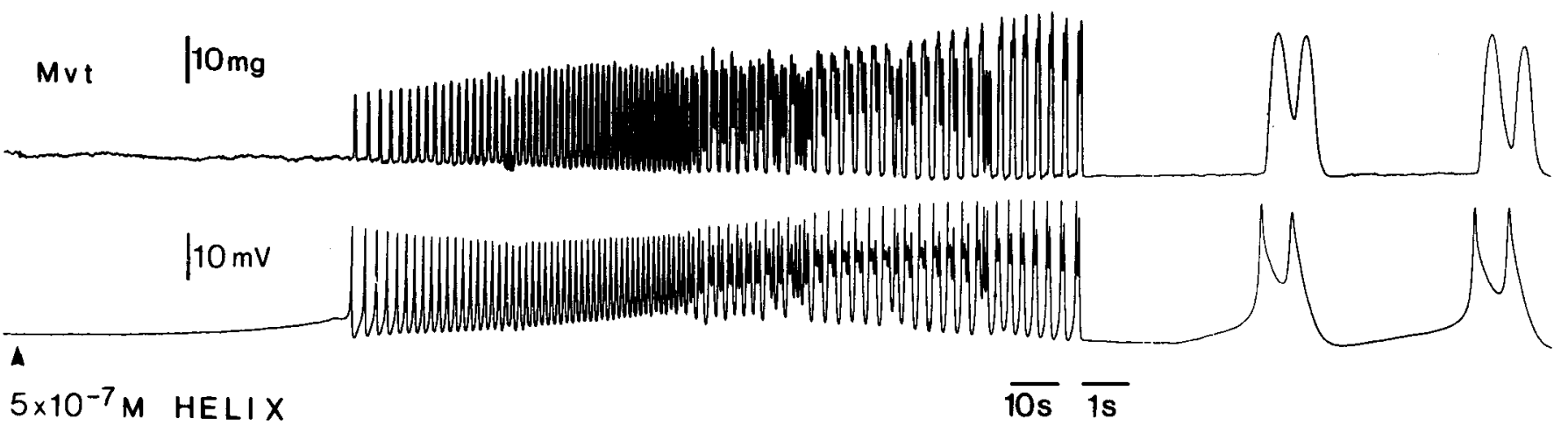

Figure 8. Rhythmic contractions in the dilator muscle are associated with rhythmic oscillations of membrane potential. Simultaneous movement (Mvt, top trace) and intracellular (bottom trace) recordings from a single cpvi bundle. Helix peptide was added to the bath at the upward arrow. Note the slight depolarization of the fiber that precedes the onset of rhythmic contractions. The right-hand section of the recording is a faster chart speed to show that the oscillations in membrane potential lead the rhythmic contractions. 
Figure 9. YGGFMRFamide-evoked depolarizations are associated with a decrease in input conductance of the muscle fiber. Two microelectrodes were placed in a muscle fiber. $A$, Slow time base recording. Top trace, membrane potential (cpvl). Resting potential indicated by arrowhead. Bottom trace, current monitor (i). Hyperpolarizing constant current pulses were passed into the fiber to monitor muscle fiber input impedance. $2.5 \times 10^{-7} \mathrm{M}$ YGGFMRFamide was added to the bath for the time indicated with the black bar. Slow time base recording shows the slow depolarization produced by the peptide. $B$, Fast-sweep recordings showing the membrane potential deflections produced by a constant current pulse in control saline (position indicated by open star in $A$ ), in the presence of 2.5 $\times 10^{-7} \mathrm{M}$ peptide (position indicated by black star in $A$ ), and in the wash (position indicated by open star in black circle in $A$ ). Note the larger deflections of membrane potential and the slight depolarization of the baseline indicated by the displacement of the traces. $C$, Full voltage-current plot from the same muscle fiber showing that the input impedance of the fiber was increased in the voltage range of $-100 \mathrm{mV}$ to -60 $\mathrm{mV}$ by the peptide.
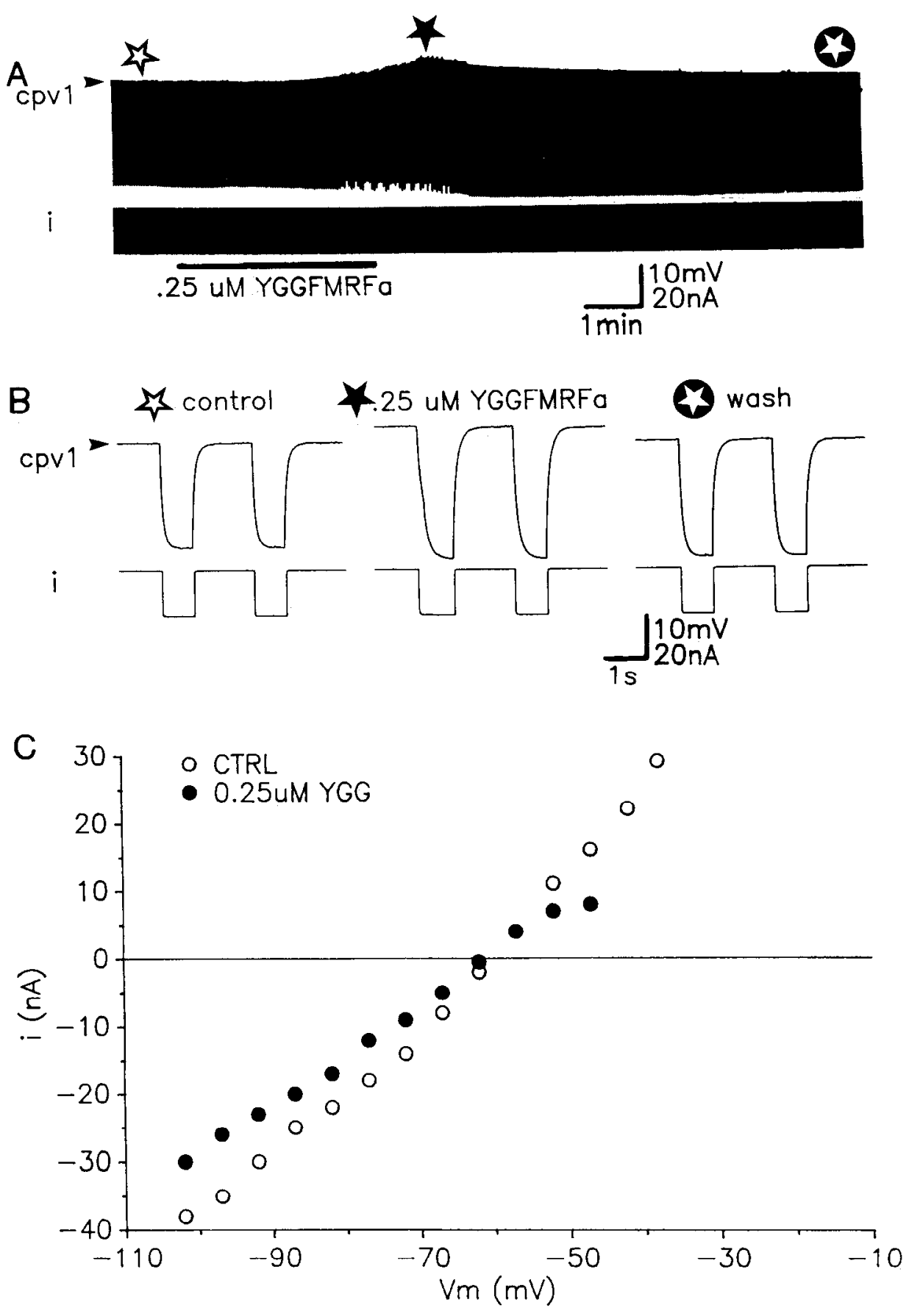

At $t=20 \mathrm{sec}$, the pulse elicited small oscillations. At $t=40$ sec, though the fiber was not spontaneously oscillating, the depolarization of the fiber produced full oscillations. Note that the muscle produced oscillations at a membrane potential that failed to evoke oscillations under control conditions. Between $t=60$ sec and the next pulse in Figure $11 B$ the muscle fiber started spontaneous rhythmic activity. When the muscle was depolarized during spontaneous activity (last pulse in Fig. $11 B$ ) the frequency of the oscillations increased during the pulse, as expcctcd for an oscillator. Following the wash (Fig. 11C), the muscle reverted to its passive state.

\section{Consequence of peptide-induced oscillations for neuromuscular} functions

FMRFamide and similar peptides elicit bouts of contractions when applied to the cpv1 muscle. It is therefore important to determine what consequences these effects will have for the muscle's response to rhythmic excitatory neural inputs. In neurogenic systems, muscles will depolarize and contract only in response to neurally released neurotransmitter. In this case the muscle is a "slave" of the innervating motor neurons. Alternatively, if the muscle is capable of producing triggered regen- 


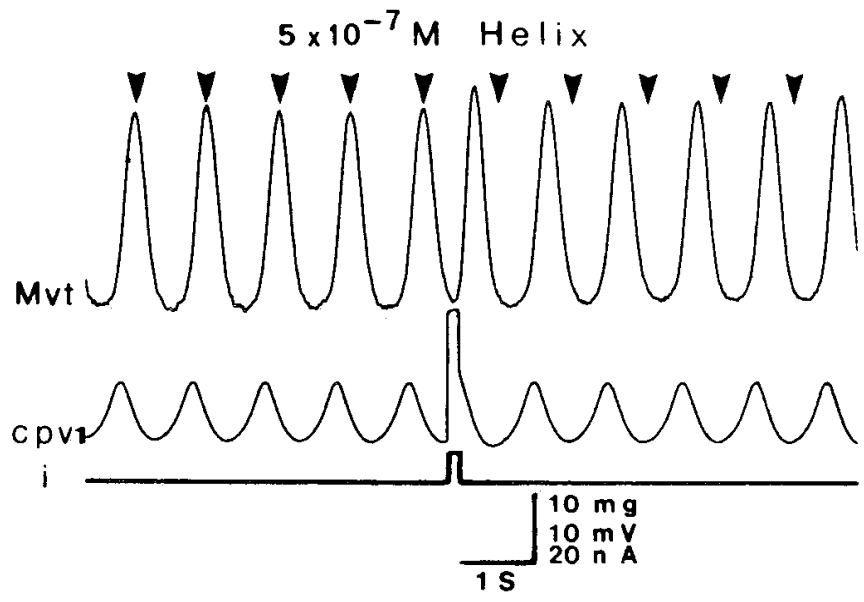

Figure 10. Resetting of the ongoing muscle rhythm by short depolarizing pulse of current injected into the muscle fiber. Simultaneous movement $(M v t)$ and intracellular recordings $(c p v l)$ from a single isolated bundle of the dilator muscle. A $150 \mathrm{msec}$ depolarizing pulse of current (i) was passed into the muscle fiber. Arrowheads indicate the expected time of contraction in the absence of the experimental perturbation. This record was made in the presence of $5 \times 10^{-7} \mathrm{M}$ Helix peptide. erative plateaus or action potentials, even modest depolarizations that result from motor neuron activity can produce large amplitude contractions.

Figure 12 compares the contraction produced in a muscle in control saline with one in the presence of peptide when a PD motor neuron is depolarized intracellularly. In control saline a single burst of high frequency action potentials (Fig. 12A) evokes no measureable contraction, and repeated bursts evoke (Fig. $12 C)$ only small contractions. However, in the presence of YGGFMRFamide, a single presynaptic burst (Fig. 12B) or trains (Fig. 12D) evoked contractions more than 100 times larger than those evoked in the absence of the peptide. The large amplification of contraction seen in peptide occurs because of the regenerative properties of the muscle demonstrated in Figure 11.

The PD neurons themselves can be silent, such as seen in Figure 11, or can be rhythmically active when central inputs to the STG are stimulated (Meyrand and Moulins, 1988b). True oscillators, such as the cpv1 muscle in its spontaneously active state, can only be entrained in a narrow frequency range. Therefore, if the muscle and motor neurons are both rhythmically active, but at significantly different frequencies, it is unlikely that the rhythmically active motor neurons could drive the mus-
A control
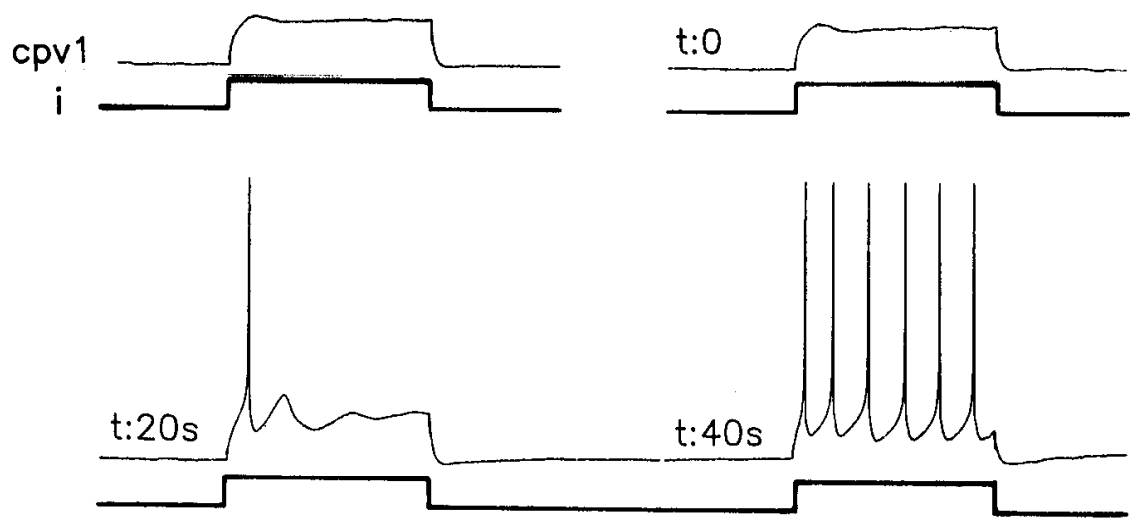

B

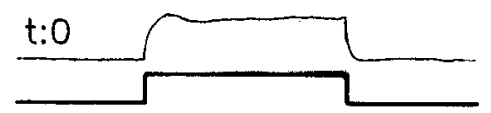

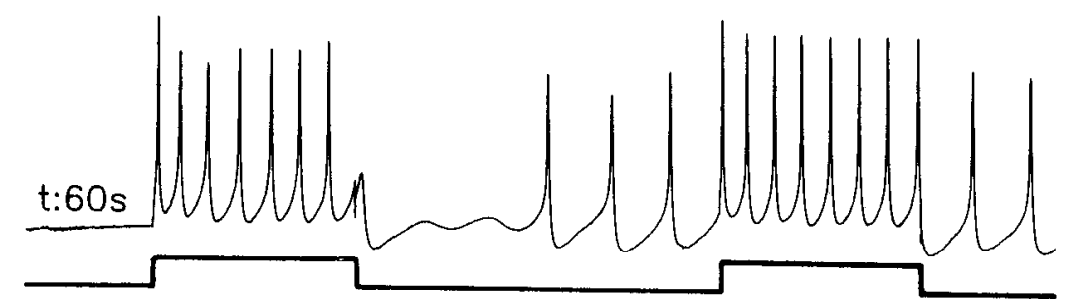

C

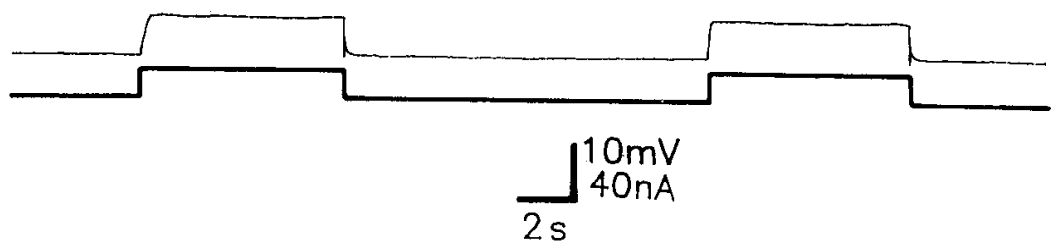

Figure 11. YGGFMRFamide modifies the response of the muscle fiber to injected current. Two microelectrodes were placed in a muscle fiber. In all records the top trace is membrane potential and the bottom trace is the current passed into the fiber with the second microelectrode. $A$, Depolarizing current pulse passively depolarized the muscle fiber membrane. $B$, at $t=0,2.5$ $\times 10^{-7} \mathrm{M}$ YGGFMRFamide was added to the bath. The response of the muscle to the same size depolarizing current pulse is shown at $t=0, t=20 \mathrm{sec}, t=$ $40 \mathrm{sec}, t=60 \mathrm{sec}$, and $t=80 \mathrm{sec}$ (the last depolarization was at $t=80 \mathrm{sec}$, but not so labeled on the figure because of space). $C$, The response to the same amplitude depolarizing current pulse shown after washing with control saline for $30 \mathrm{~min}$. 
A

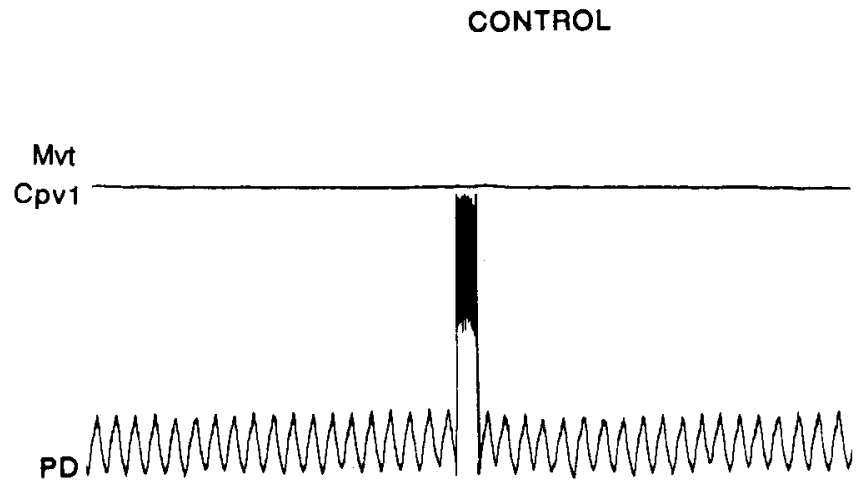

C
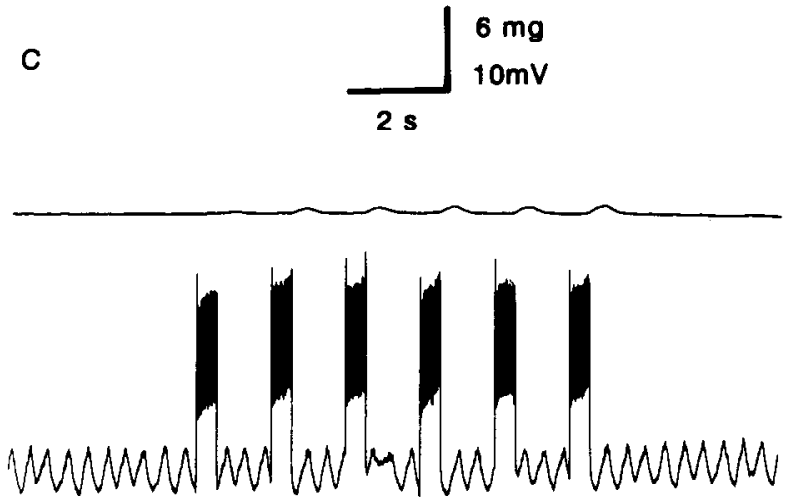
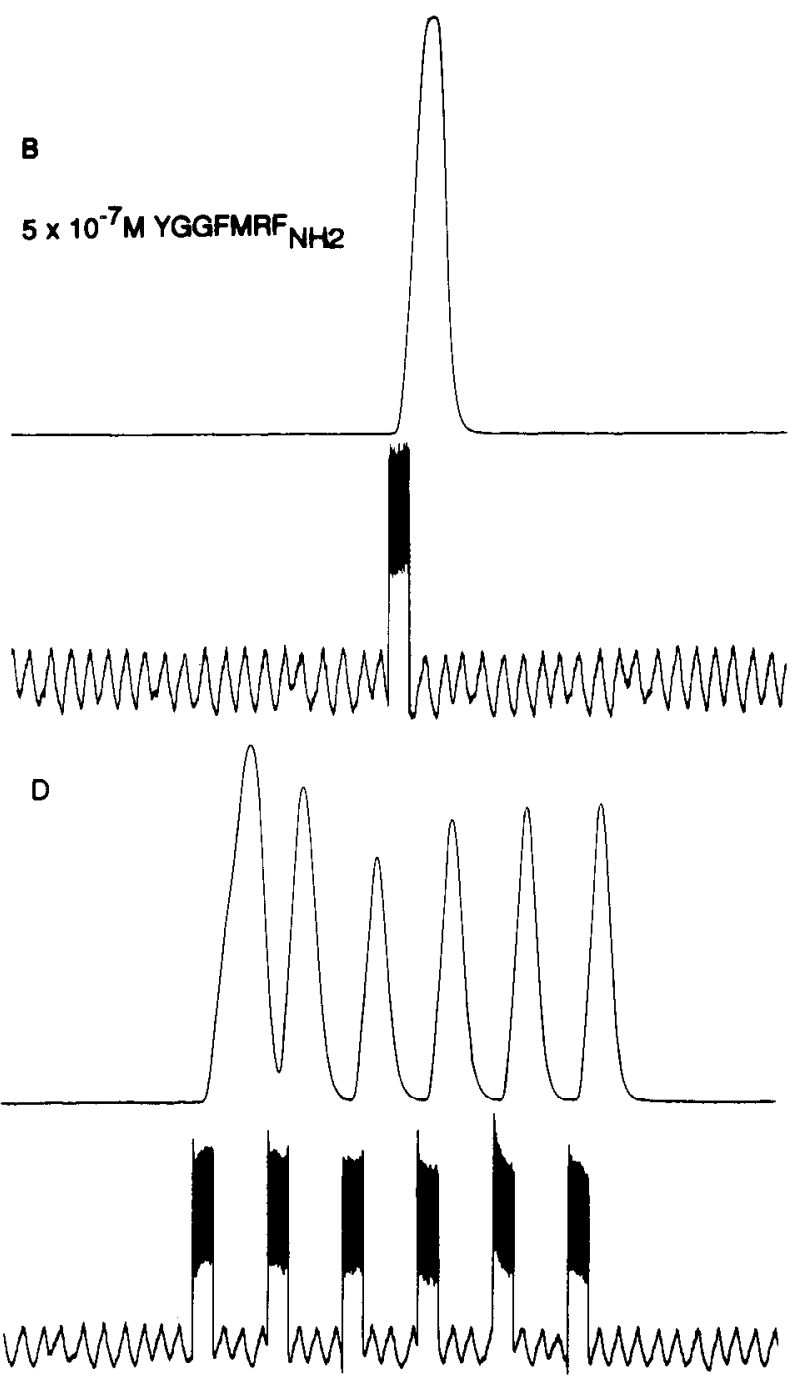

Figure 12. Peptide enhancement of the muscle contraction produced by stimulation of a PD motor neuron. The PD motor neuron soma was depolarized intracellularly, and the movements of the cpv1 muscle were recorded. $A$, Single burst of action potentials in the motor neuron evoked no measureable contraction. $B$, Large amplitude contraction evoked by intracellular depolarization in peptide. $C$, Repeated bursts of action potentials in PD motor neuron evoked small contractions in muscle in control saline but evoked large amplitude contractions in peptide, $D$.

cle in a one-for-one manner through the entire frequency range of the pyloric rhythm. However, if the muscle were not spontaneously active but displayed regenerative properties when depolarized (as in Fig. $11 B$ ), the muscle would be able to generate large amplitude contractions (such as seen in Fig. 12B) in response to rhythmic motor neuronal activity, regardless of the pyloric rhythm frequency. This is illustrated in the experiments shown in Figure 13.

The left panel in Figure 13 shows a muscle in control saline. Under these conditions the muscle was inactive (top). When the innervating motor nerve was stimulated in a single burst a small movement occurred (Fig. 13B), and when the motor nerve was stimulated in repetitive bursts, the muscle generated a small movement in response to each motor neuron burst (Fig. 13C).

The middle vertical panel in Figure 13 shows a muscle that was spontaneously contracting in the presence of YGGFMRFamide. Figure $13 B$ shows that a single burst of stimuli to the motor nerve was able to reset this spontanous activity. However, Figure $13 C$ shows that when the motor nerve was stimulated rhythmically, to mimic the pyloric rhythm, the muscle was not able to follow the motor neuron stimulation at all frequencies, and the resultant muscle movements were a disorganized composite of nerve-evoked and spontaneous activity. Thus, here we have a failure of the motor neuron to entrain the muscle it innervates because of the strong expression of the regenerative properties of the muscle.

The right vertical panel was taken from a muscle still in peptide that had stopped spontaneously oscillating. Here, the amplitude of the muscle movement evoked by a single train of stimuli to the motor nerve was dramatically increased (compare left and right panels of Fig. 13B). Most importantly, when the motor nerve was stimulated repetitively to mimic the pyloric rhythm, the muscle generated large movements that followed one-for-one each burst of motor neuronal activity. Thus, the peptide-induced state in which the muscle is not spontaneously active, but in which the muscle can be induced to show oscillatory properties when depolarized, allows the muscle to generate large movements in response to rhythmic motor neuronal inputs that can follow the dynamic range of the presynaptic neuronal activity. 


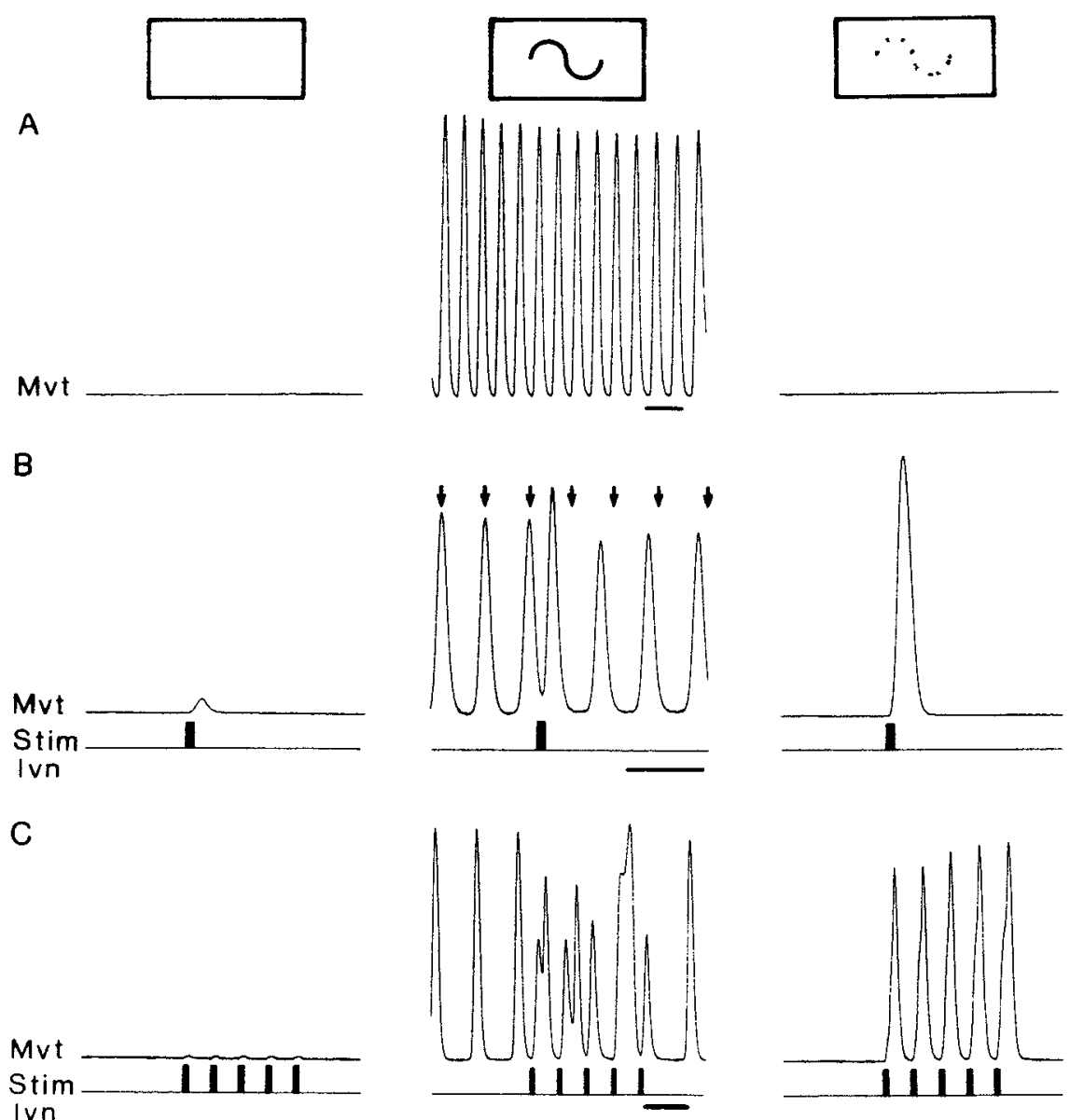

Figure 13. Functional consequences of the state of the muscle for neuromuscular control. Left vertical panel, muscle in a "nonoscillatory state" (empty white box) in the absence of peptide. Center vertical panel, muscle oscillating in the presence of peptide (solid oscillator symbol). Right vertical panel, muscle capable of producing single oscillations when stimulated or depolarized but not spontaneously rhythmic (dashed oscillator symbol). Muscle is found in this state in the presence of peptide, either directly before the onset of rhythmic contractions or after a bout of rhythmic contractions has stopped. $A$, movement recordings showing the behavior of the muscle in its 3 modes in the absence of nerve stimulation. $B$ Movement recordings showing the response of the muscle to a single train of stimuli to the lvn. $C$, Movement recordings showing the response of the muscle under these 3 conditions to repeating trains of stimuli that mimic physiological conditions in which the motor neurons are rhythmically active.

\section{Discussion \\ Distribution and characterization of FMRFamide-like immunoreactivity}

There are 2 interesting features of the distribution of FMRFamide-like peptides in the stomatogastric nervous system of the shrimp, Palaemon serratus. First, as in other crustaceans such as lobsters and crabs (Marder et al., 1987), there is intense staining throughout the neuropil of the STG. However, unlike the other species thus far studied, several STG neurons showed FMRFamide-like immunoreactivity. This is even more surprising because in the previously studied species none of the STG somata stain with antisera raised against a variety of amines and peptides (Marder, 1987; Marder and Nusbaum, 1989). We do not know which STG somata contain the FMRFamide-like peptide(s) but they are not the motor neurons to the dilator muscle (Fig. 3). Second, stained fibers were clearly seen in the motor nerves of the stomatogastric nervous system, including those that innervate the dilator muscle. This suggests that a FMRFamide-like peptide may be released in the vicinity of the dilator muscle. We do not yet know the source of the FMRFamide-like fibers, or how they are likely to be physiologically activated.

Both of the antisera used for these studies (231 of O'Donohue et al., 1984 and 671 of Marder et al., 1987) are reasonably specific for peptides of the FMRFamide-like family but will react with many, if not all, peptides that contain a terminal MRFamide or a LRFamide. Therefore, the sequence of the
FMRFamide-like peptide(s) found in the shrimp nervous system is an open question. Because other arthropod species show a number of different extended FMRFamide-like peptides (Trimmer et al., 1987; Nambu et al., 1988; Robb et al., 1989; Price and Greenberg, 1989), it is possible that the shrimp nervous system also produces several different FMRFamide-like peptides. Several other arthropod preparations contain extended FLRFamide peptides and are more sensitive to these than to extended FMRFamide-like peptides (Price and Greenberg, 1989). Thus, it is interesting that on the shrimp muscle preparation the extended FMRFamide-like peptides are strongly physiologically active.

\section{Modulation of muscles and neuromuscular junctions}

In many preparations the ability of muscles to generate action potentials or plateau potentials is under modulatory control (Lingle, 1981; Glusman and Kravitz, 1982; Calabrese and Maranto, 1984; Evans and Myers, 1986a; Meyrand and Moulins, 1986; Calabrese, 1989). Moreover, in many preparations modulatory substances, among them the FMRFamide-like peptides, are likely to have multiple sites of action, including presynaptic terminals as well as the muscles themselves (Beltz and Kravitz, 1986; Evans and Myers, 1986a,b; Calabrese, 1989; Mercier et al., 1989). Although it is not the focus of this study, FMRFamide-like peptides potentiate the amplitude of the synaptic potentials evoked by motor neuron stimulation in the dilator muscle (P. Meyrand and E. Marder, unpublished observations). 


\section{Multiple modulators}

The dilator muscle responds similarly to both dopamine (Meyrand and Moulins, 1986) and the FMRFamide-like peptides. Assuming that both of these substances reach the dilator muscle, either through direct neuronal pathways or hormonally, this poses 2 questions: (1) whether these 2 substances are physiologically released at different times, and (2) whether they act by the same or different mechanisms.

The cpv1 muscle is not unusual in receiving multiple modulatory inputs. For example, the well-studied Accessory Radula Closer (ARC) muscle in Aplysia is modulated by a variety of amines and peptides (Weiss et al., 1978; Lloyd et al., 1984; Cropper et al., 1987a,b). The myogenic rhythm of the locust hindleg is modulated by a number of amines and peptides (Evans and Myers, 1986a,b). Thus, multiple modulatory inputs to a muscle may turn out to be the rule rather than the exception, though the physiological consequences of this are unclear (Calabrese, 1989).

\section{Physiological consequences of the conditional oscillatory properties of the dilator muscle}

When spontaneously contracting, the cpvl muscle displays all the characteristics of an endogenous oscillator (Meyrand and Moulins, 1986): (1) the frequency of the oscillation is voltage dependent (Fig. $11 B$ ), (2) the response to a brief stimulus is allor-none, (3) the ongoing rhythm can be reset by a brief stimulus to the muscle itself (Fig. 10), and (4) the endogenous rhythm can be entrained by cyclic stimulation, when the stimulus is close in frequency to the intrinsic frequency of the muscle (Meyrand and Moulins, 1986). However, unlike the vertebrate heart or some myogenic insect skeletal muscles (Hoyle, 1978), the cpv1 muscle shows 3 states of activity: (1) spontaneous oscillatory activity, (2) passive follower behavior, or (3) a triggered slow spike or single oscillation. The ability of the muscle to display these 3 different states means that the response of the muscle to a given pattern of motor neuronal stimulation will be remarkably different. Indeed, each of these states may be suited to a different physiological context.

In its quiescent "control" mode, the muscle contracts vigorously only when the motor neurons fire in dense, high frequency bursts; otherwise only small movements result. In the spontaneously oscillatory mode, the muscle can provide rhythmic movements even in the absence of a neuronal input. Since both dopamine and FMRFamide-like peptides can induce this spontaneous activity, it is possible that hormonally released modulators can provide a non-neural activation of the muscle. In its third state, the muscle produces vigorous movements in response to even modest levels of motor neuron activity. In this state the regenerative properties of the muscle act as an "amplifier" for the synaptically released neurotransmitter, because even a small depolarization is sufficient to trigger a full large depolarization and contraction of the muscle. Furthermore, in this state the muscle can follow faithfully almost any pattern of motor neuron discharge, which is not always possible when the musclc is spontancously oscillatory (Fig. 13).

In the laboratory the application of dopamine or FMRFamide-like peptides triggers spontaneous oscillations that last for hundreds of seconds or minutes, and then stop, to be succeeded by the state in which the muscle is sensitive to small depolarizations. It is possible that in the animal these modulatory substances are released more slowly so that the muscle does not actually go through a full oscillatory mode, but makes a smooth transition between our "control" mode and the "amplifier" mode. However, without knowing the kinetics and site of modulator release, this is difficult to determine. A challenge for the future will be to understand how and when the FMRFamide-like peptides are released in the animal and how these are used behaviorally.

\section{References}

Atwood HL (1976) Organization and synaptic physiology of crustacean neuromuscular systems. Prog Neurobiol 7:291-381.

Beltz BS, Kravitz EA (1986) Aminergic and peptidergic neuromodulation in crustacea. J Exp Biol 124:115-141.

Calabrese RL (1989) Modulation of muscle and neuromuscular junctions in invertebrates. Sem Neurosci 1:25-34.

Calabrese RL, Maranto AR (1984) Neural control of the hearts in the leech, Hirudo medicinalis. III. Regulation of myogenicity and muscle tension by heart accessory neurons. J Comp Physiol A 154:393-406.

Callaway JC, Masinovsky B, Graubard K (1987) Co-localization of $\mathrm{SCP}_{\mathrm{B}}$-like and FMRFamide-like immunoreactivities in crustacean nervous systems. Brain Res 405:295-304.

Cropper EC, Lloyd PE, Reed W, Tenebaum R, Kupfermann I, Weiss KR (1987a) Multiple neuropeptides in cholinergic motor neurons of Aplysia: evidence for modulation intrinsic to the motor circuit. Proc Natl Acad Sci USA 84:3486-3490.

Cropper EC, Tenebaum R, Gawinowicz Kolks MA, Kupfermann I, Weiss KR (1987b) Myomodulin: a bioactive neuropeptide present in an identified cholinergic buccal motor neuron of Aplysia. Proc Natl Acad Sci USA 84:5483-5486.

Dixon D, Atwood HL (1989) Adenylate cyclase system is essential for long-term facilitation at the crayfish neuromuscular junction. J Neurosci 9:4246-4252.

Evans PD, Myers CM (1986a) Peptidergic and aminergic modulation of insect skeletal muscle. J Exp Biol 124:143-176.

Evans PD, Myers CM (1986b) The modulatory actions of FMRFamide and related peptides on locust skeletal muscle. J Exp Biol 126: 403-422.

Glusman S, Kravitz EA (1982) The action of serotonin on excitatory nerve terminals in lobster nerve-muscle preparations. J Physiol (Lond) 325:223-241.

Hooper SL, Marder E (1984) Modulation of a central pattern generator by two neuropeptides, proctolin and FMRFamide. Brain Res 305: 186-191.

Hoyle $G$ (1978) Intrinsic rhythm and basic tonus in insect skeletal muscle. J Exp Biol 73:173-203.

Kuhlman JR, Li C, Calabrese RL (1985) FMRFamide-like substances in the leech. II. Bioactivity on the heartbeat system. J Neurosci 5: 2310-2317.

Li C, Calabrese RL (1987) FMRFamidelike substances in the leech. III. Biochemical characterization and physiological effects. J Neurosci 7:595-603

Lingle C (1981) The modulatory action of dopamine on crustacean foregut neuromuscular preparations. J Exp Biol 94:285-299.

Lloyd PE, Kupfermann I, Weiss KR (1984) Evidence for parallel actions of a molluscan peptide $\left(\mathrm{SCP}_{\mathrm{B}}\right)$ and serotonin in mediating arousal in Aplysia. Proc Natl Acad Sci USA 81:2934-2937.

Maranto AR, Calabrese RL (1984) Neural control of the hearts in the leech, Hirudo medicinalis. II. Myogenic activity and its control by heart motor neurons. J Comp Physiol 154A:381-391.

Marder E (1987) Neurotransmitters and neuromodulators. In: The crustacean stomatogastric system (Selverston AI and Moulins, M eds). pp 262-306. Heidelberg: Springer.

Marder E, Nusbaum MP (1989) Peptidergic modulation of the motor pattern generators in the stomatogastric ganglion. In: Perspectives in neural systems and behavior, pp 73-91. New York: Liss.

Marder E, Calabrese RL, Nusbaum MP, Trimmer B (1987) Distribution and partial characterization of FMRFamide-like peptides in the stomatogastric nervous systems of the rock crab, Cancer borealis, and the spiny lobster, Panulirus interruptus. J Comp Neurol 259:150163.

Mercier AJ, Schiebe M, Bradacs H, Atwood HL (1989) FMRFamidelike peptides modulate phasic neuromuscular synapses in crustaceans. Soc Neurosc Abstr 15:25. 
Meyrand P, Moulins M (1986) Myogenic oscillatory activity in the pyloric rhythmic motor system of Crustacea. J Comp Physiol A 158: 489-503.

Meyrand P, Moulins M (1988a) Phylogenetic plasticity of crustacean stomatogastric circuits. I. Pyloric patterns and pyloric circuit of the shrimp, Palaemon serratus. J Exp Biol 138:107-132.

Meyrand P, Moulins M (1988b) Phylogenetic plasticity of crustacean stomatogastric circuits. II. Extrinsic inputs to the pyloric circuit of the shrimp, Palaemon serratus. J Exp Biol 138:133-153.

Meyrand P, Golowasch J, Marder E (1987) FMRFamide and related peptides switch a crustacean muscle into an oscillatory mode. Soc Neurosci Abstr 13:1256.

Nambu JR, Murphy-Erdosh C, Andrews PC, Feistner GJ, Scheller RH (1988) Isolation and characterization of a Drosophila neuropeptide gene. Neuron 1:55-61.

O'Donohue TL, Bishop JF, Chronwall BM, Groome J, Watson WH III (1984) Characterization and distribution of FMRFamide immunoreactivity in the rat central nervous system. Peptides 5:563-568.

Price DA, Greenberg MJ (1989) The hunting of the FaRPs: the distribution of FMRFamide-related peptides. Biol Bull 177:198-205.
Price DA, Cottrell GA, Doble KE, Greenberg MJ, Jorenby W, Lehman HK, Riehm JP (1985) A novel FMRFamide-related peptide in $\mathrm{He}$ lix: pQDPFLRFamide. Biol Bull 169:256-266.

Robb S, Packman LC, Evans PD (1989) Isolation, primary structure and bioactivity of SchistoFLRFamide, a FMRFamide-like neuropeptide from the locust, Schistocerca gregaria. Biochem Biophys Res Comm 160:850-856.

Trimmer BA, Kobierski LA, Kravitz EA (1987) Purification and characterization of FMRFamidelike immunoreactive substances from the lobster nervous system: isolation and sequence analysis of two closely related peptides. J Comp Neurol 266:16-26.

Watson WH III, Groome JR, Chronwall BM, Bishop F, O'Donohue TL (1984) Presence and distribution of immunoreactive and bioactive FMRFamide-like peptides in the nervous system of the horseshoe crab, Limulus polyphemus. Peptides 5:585-592.

Weiss KR, Cohen JL, Kupfermann I (1978) Modulatory control of buccal musculature by a serotonergic neuron (metacerebral cell) in Aplysia. J Neurophysiol 41:181-203. 